\title{
Apple vs. Mangosteen: A Qualitative Study of Students' Perception towards Native and Non-Native English-Speaking Teachers
}

\author{
Nabilah Mhd Fauzi ${ }^{1}$ \\ Harwati Hashim $^{2 \rtimes}$ \\ ${ }_{1.2}^{2}$ Universiti Kebangsaan Malaysian, Malaysia \\ 'Email:nabilahmhdfauzi@gmail.com \\ 'Email: harwati@ukm.edu.my
}

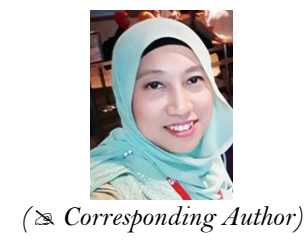

Abstract

Recruiting native English-speaking teachers to teach the target language is becoming a prevailing practice in many countries. Concerns arise in the field of ESL teaching due to this sharp increase in the number of inexperienced NEST teaching. While there is an influx of qualified Non-native English-speaking teachers (NNEST) globally, it is still much easier for untrained Native Englishspeaking teachers (NEST) to be employed. The present study investigated students' perspectives of both types of teachers and whether as time progressed will affect their respective views. This study was done in one of the schools in Malaysia. Data was collected through essay writing. The findings revealed that most of the students initially had negative perception towards NNESTs especially when it comes to teaching grammar and oral skills. On the other hand, the NESTs despite being viewed favorably at the beginning of the study, received an increase of negative receptions from students. Despite the different attributes shown by both types of teachers - they complement each other. Students agreed that collaborative teaching is a better way when addressing this dichotomous world of NESTs and NNESTs.

Keywords: Native English-speaking teachers (NEST), Non-native English-speaking teachers (NNEST), English as a second language (ESL), ESL teaching, Grammar, Oral skills, Qualitative study.

Citation | Nabilah Mhd Fauzi; Harwati Hashim (2020). Apple vs. Mangosteen: A Qualitative Study of Students' Perception towards Native and Non-Native English-Speaking Teachers. Journal of Education and e-Learning Research, 7(2): 218-228.

\section{History:}

Received: 1 May 2020

Revised: 9 June 2020

Accepted: 13 July 2020

Published: 20 July 2020

Licensed: This work is licensed under a Creative Commons

Attribution 3.0 License (cc))

Publisher: Asian Online Journal Publishing Group
Acknowledgement: Both authors contributed to the conception and design of the study.

Funding: This research is funded by Universiti Kebangsaan Malaysia (UKM) under the research grant no. GG-2019-077 and GGPM-2019-037.

Competing Interests: The authors declare that they have no conflict of interests.

Transparency: The authors confirm that the manuscript is an honest, accurate, and transparent account of the study was reported; that no vital features of the study have been omitted; and that any discrepancies from the study as planned have been explained.

Ethical: This study follows all ethical practices during writing.

\section{Contents}

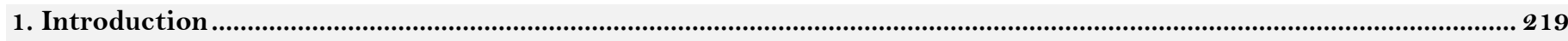

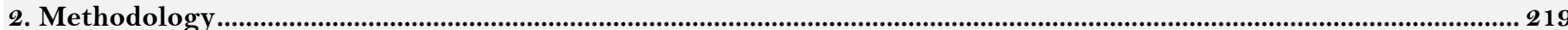

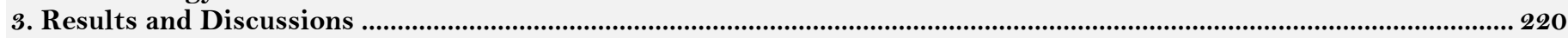

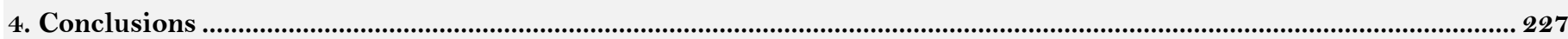

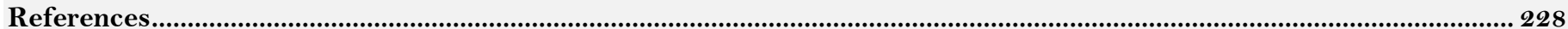




\section{Contribution of this paper to the literature}

This study contributes to the existing literature by investigating students' perceptions towards Native English-speaking teachers (NEST) and Non-native English-speaking teachers (NNEST).

\section{Introduction}

One of the reasons why the NEST is highly demanded by the administrators is because they perceive that it is unlikely for the EFL students to choose NNEST (Non-native English-speaking teachers) over NEST (Native English-speaking teachers) as their teachers. This trend not only results in the unprecedented growing issues surrounding non-native speakers, it also significantly affects how the public values NNEST. However, these native speaker fallacious beliefs regarding a NEST is the model of language correctness and that qualified teachers should only be native in the language; unfortunately, do not coincide with many studies.

The term "native speaker" itself has now considered a moot point as globalisation makes English no longer exclusive to certain countries. Littlewood (1984) in his defence, believed that when someone is considered a native speaker, they should be labelled as proficient instead. "The native speaker is nothing but 'a figment of linguist's imagination'... and it is more apt to use the term 'proficient user' of a language when referring all speakers who can successfully use the language (Moussu \& Llurda, 2008). This also brings us to another question to ponder whether merely knowing how to describe one's native language, will make someone a skilful ESL teacher. Language teaching requires more than superiority in English competency (Hashim, Yunus, \& Hashim, 2018; Hashim., Yunus, \& Hashim, 2019). It is more than being a native speaker; it demands a great deal of training and practice and this is also supported by Abdullah, Yunus, and Hashim (2019) and Abdullah. et al. (2019).

Nevertheless, this paradoxical controversy of this dichotomy in language and teaching follows when the MOE, in collaboration with the Malaysian-American Commission on Educational Exchange (MACEE), decided to introduce the English Teaching Assistant (ETA) program. This ETA program that began in 2006, annually places native speakers from the U.S. in rural Malaysian secondary schools. While it aims to foster interest in learning English Language among Malaysian students and provides an opportunity for cultural exchange to both the ETAs and the host communities, this programme has since been garnering mixed receptions across the country.

Although there are several past studies done to evaluate students' perceptions towards NESTs and NNESTs, most of the studies were done in EFL countries where English is taught as a foreign language. This matters greatly as there is a great difference of how people value teaching and learning in English between countries in the outer circle and the expanded circle of Kachru's World of Englishes, in which, the first learns English as a second language (ESL) rather as a foreign language. It is definitive that Malaysia is an ESL country since English is used as the language of instruction in schools and formal governmental matters.

Additionally, none of the prior studies had specifically examined Malaysian students' perception towards NEST and NNEST. Previous studies were also controversial because most of them made comparison between NESTs and foreign teachers who speak English. Clearly, they had posited an unlikely outcome than when having local teachers who teach English themselves. Hence, a provincial study must be done.

For some time, the status of NESTs within the English teaching community has been controversial and challenged. Some researchers claim that NESTs are more successful in teaching than NNESTs as they are the model of the language, while others still hold firm to the thought that skill plays a pivotal role in teaching. The primary focus of this study was to investigate the characteristics of NESTs and NNESTs. The second purpose was to determine students' attitudes towards NESTs and NNESTs.

Three research questions guided this study:

1. Is there any significant difference between NESTs and NNESTs in teaching English as a second language?

2. What is the perspective of students towards NESTs and NNESTs?

3. Does the length of exposure to their ESL teachers influence students' perspective towards NESTs and NNESTs?

As with the majority of studies, this study has to be viewed in light of some limitations. As there is almost to scant scientific or academic research ever conducted in Malaysia on the ETA, NNEST, and NEST, most of the literature used in this study is based on other countries that may differ in a certain manner that will affect the result of this study. Moreover, although currently there are about 99 schools in Malaysia that have been receiving the ETAs as NESTs, this study will have to limit its scope to only one school in Perak due to the time constraint as well as in terms of cost for the researcher's mobility. As a result, the data from this study might be less robust for states and schools that are not visited and included in this study. A more extensive study will be recommended as future research.

\section{Methodology}

To elicit student's perceptions towards NESTs and NNESTs, a total of 30 secondary school students from a school in Malaysia were recruited in this study. These students were selected conveniently among those who have been learning from both types of teachers for a year. These students came from various backgrounds. The sampling will not be stratified since only a few classes had NESTs as teachers; the biographical information about these students were not collected to maintain complete discretion. Following this, the respondents were thus, not randomly assigned. Using a table of random numbers, the names of students will be selected until a minimum of 30 students was obtained. It is anticipated that if fewer than 30 students per setting initially respond to the instruments described below, names will continue to be drawn from the remaining individuals until at least 30 students from the school have completed the essay. The study will have 30 students as samples as suggested by the finite table of Krejcie and Morgan (1970).

\section{a) Instrument}

Most research done in the field of language attitudes and perceptions are inclined to employ one of these methods: 1) Societal treatment, 2) direct measurement and 3) indirect measurement. While these three methods have been widely used in research on language attitudes, their validity and reliability are uncertain and among all 
of them. More importantly, the technique forces subjects to respond along the continuum that have been predetermined by researchers, instead of along dimensions of their own choice. Therefore, to avoid these problems, especially the last one listed, this study will also employ discourse-analytic technique to explore the students' perceptions towards NESTs and NNESTs at a school in Malaysia.

Following the technique, the 30 respondents were then asked to write an essay of a specified writing stimulus in order to elicit students' perceptions of NNESTs and NESTs. The writing prompt was:

Some students think that only native speakers (ETAs) can be good language teachers. Others think that nonnatives (Malaysian teachers) can also be great teachers. What is your opinion about this? Please feel free to include details and examples.

From the stimulus above, complete impartiality was maintained in the statement. Students were, therefore, free to explore and write their own perceptions regarding this issue. The same writing prompt was given during the pre-test and the post-test. The discrepancy between the two essays were taken into account. A table was tabulated to elucidate and make a comparison between the findings. The responses were collected and coded. There would not be any priori categories, this study would let the categories emerge from the data and determine whether the responses were positive or negative. The rationale for not having predetermined categories was to prevent the possibility of discarding other uncategorised dynamics in the data.

Students' responses to the writing prompts were analysed using a 'discourse-analytic' technique. The grounded theory, which was first introduced by Glaser and Strauss (1967) was initially designed to be used in sociology but the approach has been extensively used in other social sciences too (Babchuk, 1997). It should be noted that since the objective of the present study is only to examine students' perceptions towards NESTs and NNESTs, the method had been simplified. However, in modifying the application of the theory, one of its strongest tenets has been maintained: analysis is grounded in the actual data and is not based on a set of predetermined categories. Additionally, positive comments were marked '+' and negative comments were marked '-'.

There were ten categories founded based on the issues marked during the coding process. From the essays retrieved from the study, students also tend to discuss several issues in regards of NESTs and NNESTs. Therefore, these kinds of statements will be included in multiple categories. The categories that emerged from the data included: oral skills, literacy skills, grammar, vocabulary, culture, ability to answer questions, experiences as a second language student, teaching methodology, effort, and affect. These categories were further reduced into three broad groups, including: 1) Linguistic factors, 2) Teaching styles, and 3) Personal factors. While those essays will contain these categories, it was worth categorising them into those with positive and negative comments. Positive comments are marked '+' and negative comments are marked '-'.

\section{Results and Discussions \\ a. Linguistic Factors}

There were five categories that students referred to in their discussion of NESTs or NNESTs. The distribution of comments during the pre-test across these factors is given in Table 1 below:

Table-1. Distribution of comments for the 5 linguistic factors.

\begin{tabular}{|c|c|c|c|c|c|}
\hline & & \multicolumn{2}{|c|}{ NESTs } & \multicolumn{2}{|c|}{ NNESTs } \\
\hline & & + & - & + & - \\
\hline \multirow[t]{2}{*}{ Oral Skills } & Pre & 21 & $\mathrm{O}$ & 10 & -20 \\
\hline & Post & 24 & -5 & 15 & -5 \\
\hline \multirow[t]{2}{*}{ Literacy Skills } & Pre & 6 & $\mathrm{O}$ & 0 & 0 \\
\hline & Post & 8 & -2 & 20 & $\mathrm{O}$ \\
\hline \multirow[t]{2}{*}{ Grammar } & Pre & 25 & $\mathrm{O}$ & 10 & -8 \\
\hline & Post & 10 & -15 & 25 & $\mathrm{O}$ \\
\hline \multirow[t]{2}{*}{ Vocabulary } & Pre & 26 & $\mathrm{O}$ & 18 & 0 \\
\hline & Post & 28 & -2 & 20 & $\mathrm{O}$ \\
\hline \multirow[t]{2}{*}{ Culture } & Pre & 20 & $\mathrm{O}$ & 15 & -5 \\
\hline & Post & 25 & -2 & 12 & $\mathrm{O}$ \\
\hline \multirow[t]{2}{*}{ Total } & Pre & 98 & $\mathrm{O}$ & 53 & -33 \\
\hline & Post & 95 & 26 & 92 & 5 \\
\hline
\end{tabular}

The table shows that there were a total of 184 comments in the pre-test essays distributed over the five linguistic categories. There were 98 positive and o negative comments about NESTs while there were 53 positive and 33 negative statements about NNESTs. These results will be further discussed in the following subsections. On the contrary, there were 95 positive comments for NESTs at the end of the study, which increased negative comments - 26. The NNESTs on the other hand, received 92 positive comments and a major drop in negative comments to only 5 .

\subsection{Oral Skills}

This category included comments that encompassed the teaching of listening and speaking. NESTS were deemed to be the experts in teaching oral skills. There were 100 statements made about this category and it was the highest among others. 75 of these comments discussed the NESTs' role in teaching these skills while the rest talks about NNESTs in teaching the same skill. During the pre-test all the comments related to the NESTs were positive and unanimous in stating that NESTs can provide them with the best example for pronunciation. Referring to the study done by Árva and Medgyes (2000) the communicative ability has been the forte of NESTs. The following examples illustrate students' insight of NESTs' capability to teach oral skills:

1) It is like movies, and tv series come alive. The pronunciation sounds real because it is coming from a native speaker. I believe how they pronounce the words are correct. (SS5, NEST, +) 
2) The native speakers speak like singing. They change their tones like up and down. I like listening to it. Speaking is not all the time flat. (SS15, NEST, +)

These two statements prove that students preferred to have NESTs because they can learn "the real pronunciation live". We have to keep in mind that these students come from rural school, whereby they have limited access to English input. Therefore, they rely heavily on their teachers to learn the target language.

In comparison to NESTs, NNESTs received mixed reviews when teaching oral skills. Out of the 30 initial comments that they received, 20 were negative, and only 10 were positive. The positive comments explained NNESTs' ability to detect the students' pronunciation errors and correct them immediately.

3) ...when non-native teachers detect our mistakes, the teachers will tell us immediately and help us to pronounce the words. I can remember it better that way. (SS4, NNEST, +).

On the contrary, the negative comments regarding NNESTs ability to teach oral skills mostly centralised on NNESTs' supposed non-standard pronunciation. Students felt that NNESTs were not the best teachers for oral skills because they were themselves non-native. The following statement is an example of such comments:

4) They have problems with pronunciation themselves. I have been saying the word "flour" incorrectly until I was corrected by the native speaker teacher. But then again, pronunciation is not the only thing that you can learn in an English class. (SS20, NNEST, -).

One interesting observation by a student was although not all NNEST teachers can teach pronunciation well, they may be better at teaching other skills. This can be illustrated in the following example:

5) My non-native teacher can sometimes pronounce the words wrongly. However, they are great at teaching listening. She taught us strategies in listening. So, I no longer feel scared when asked to sit in a listening test. (SS9, NNEST, -)

Additionally, this student like most other students perceive non-native teachers often fails to demonstrate good examples in pronunciation unlike the NEST that are considered standard. Reves and Medgyes (1994) stated in their study that sometimes NNEST themselves feel 'deficient' in their language skills and that they feel inferior about their inadequacy. Similarly, in justifying their inadequacy, NNESTs in Reves and Medgyes (1994) study argue that English is a learnt language, so it will not come naturally. However, these insecurities can be argued because that study was conducted in an EFL country, Hungary. It is possible that the English teachers in Malaysia will not have the same amount of insecurities as their respondents.

Looking at how the number of negative receptions reduced and there were more positive comments during the post-test could mean that initially, students have a prejudgment thought about NNESTs and that to them pronunciation in English is everything. They were easily swayed by accent. However, this opinion was contended towards the end as they find that teachers' teachers' knowledge to be a more important factor. This was proven by the majority number of positive comments towards NNESTs in comparison to NESTs.

\subsection{Literacy Skills}

Reading and writing require literacy skills. In this study, the number of comments for literacy skills were lower than those for oral skills. There were only 6 comments at the beginning of the study in this category. The comments discussed positive roles of NEST in teaching these skills. One student wrote:

6) I find that their teaching is not boring as most teachers are. Before this, it is all reading and writing. I feel scared to come to school. But we get to sing and act out with native teachers. (SS19, NEST, +)

The statement shows that NEST can be creative at teaching literacy skills. It seems that NESTs are creative at teaching literacy skills and do not use conventional techniques whereby the skill teaching is mostly a one-way effort. Students find coming to an English class less intimidating.

7) The text use for reading is not boring. Sometimes, it is about K-Pop artists. It is something that I know. I look forward to what we are going to write and read. (SS25, NEST, +)

The choice of texts could be why NEST is preferred at the beginning of the year. Students can relate to the text chosen as it is current and something that they are familiar with. NESTs even bring in songs to class to teach reading and writing. What is interesting about this too is that NESTs allow students to use the focussed language in real life and make students realise the importance of knowing the language in order to learn more about their friends in the pen-pal project. One of the students states that:

8) In one of the classes with native teachers, we need to write a to another student from another school in Terengganu. Last year we even had a chance to write to American students. I try to write better each time because I want to know more about my pen pal. (SS30, NEST, +).

Although none of the statements rates NNESTs high during the pre-test, that does not mean NNESTs are not good at teaching writing and reading. Students' perceptions change positively during post-test as 40 students make their preference to have NNESTs to teach them literacy skills. It is interesting the whopping number of increases for the positive views towards NNESTs which implies that students viewed NNESTs as better at teaching literacy skills over time. One reason for this, as given by one of the students, is that in order to be good writers both native and non-native speakers need to first learn how to write. This student said that unlike oral skills, literacy skills need to be acquired and do not come naturally like the speaking skills. According to this student:

9) I think writing is different than talking. Anyone can talk but to write and read, you need to learn them. I think the native teachers need to go to a writing class too. (SS12, NEST, -).

It is interesting that some students agree that the process of acquiring literacy and oral skills are different Literacy skills are not inherent, rather should be acquired and developed. This reminds us of an argument in which stated that the privilege of being a native speaker can be contested when dealing with written language. No one is born with the ability to read and write.

\subsection{Grammar}

Similar to literacy skills, NESTs came initially as dominant during the pre-test. 25 students gave positive comments about their grammar prowess. However, the number reduces to 10 and there were 15 negative comments for NESTs towards the post-tense. On the other hand, NNESTs were not doing well during the pre- 
test. They received only 10 positive comments and 8 negative comments at the beginning of the study. Despite the early struggle, it seemed that students favoured them better by the end of the test. The number of positive comments dramatically increased to 25 during the post-test. Additionally, in comparison to NESTs, there were no negative comments received by NNESTs too.

An example of a student's comment elaborating on NESTs' strength during the pre-test:

10) Of course, the ETAs will know grammar better because it is their language. I expect they will be able to explain about grammar better. (SS26, NEST, +)

Students expected that NESTs should be able to provide good learner models. However, the same students expressed a different view during the post-test:

11) It is a bit annoying when ETAs kept on saying that they can't explain why something is wrong or right. They will say that they feel something is wrong because they feel it that way. I can't understand it. (SS26, NEST, -).

In the beginning, students seem frustrated to be continuously corrected by NNESTs. However, the same students feel the lack of correcting by NESTs can be discomforting to them:

12) The Malaysian teachers always make corrections to my sentences. I feel unconfident to say anything in class. But the ETA never corrects my English and this keeps me worried. (SS8, NEST, -)

Conversely, students wrote positively in the post-test about NNESTs' strength as grammar teachers because they could detect errors and correct them immediately. NNEST will also explain the grammatical rules and if possible, in the students' native language:

13) The non-native teachers are really helpful at getting me ready to face my SPM. They will tell me if I make any error and they will make the correction instantly. That way, I can remember the new knowledge well. When I am with the native speaker, they will rarely highlight my error. I don't think that will help me much. Although it keeps me speaking in English but I do not think that is what I want. (SS17, NNEST, +) Not many students prefer to have grammar to be taught covertly. It was clear that from the summary of SS37, NNESTs are not afraid to point out errors and overtly correct the students. Unlike the common belief that feedback given overtly might be detrimental as it will lead to an increase of affective filter, it seems that there are students who celebrate instant correction to their errors. NNEST can convey the grammar rules better because in order for them to be English teachers, they need to do well in the English language subject in standardised tests, such as SPM and PT3. Recently, there is even the CEFR readiness examination to test English teachers' language proficiency. In contrast, NESTs know how to use the language but they are not explicitly aware of its rules. This lack of a grammatical understanding unfortunately is noticeable to students. Therefore, this leads to the present study students to label NESTs as incompetent teachers of grammar.

Another fascinating comment was:

14) I secretly think the non-native teachers know more about grammar than the ETAs. I once asked the teachers about past tense. I understand the non-native teacher's explanation better. She often tries to relate with Bahasa Malaysia. This is really helpful. (SS10, NNEST, -)

The non-native teachers also use their ability to converse in the students' mother tongue to the advantage when explaining grammatical items. It is also worth-noting from the above statement, that despite the fact native speakers can "speak the language perfectly", they are unable to teach it. Thus, this statement also links NESTs' inability to teach grammar structure to their lack of experience explicitly learning it.

\subsection{Vocabulary}

Students stated that both NESTs and NNESTs are equally could be good teachers of vocabulary. There were 44 positive comments initially. There were no negative comments on NNESTs even after the study. Nevertheless, 2 negative comments highlighted the same problem in NESTs. Hence, being a NEST do not necessarily make a native speaker a better English teacher. This can be seen in the following statement:

15) It is a bit confusing sometimes when the ETAs say the word that I always use does not mean the same in the American English. My non-native teacher says we need to use British English for SPM. So, I don't know...(SS23, NNEST, -).

The students had a terrible time telling between American and British English. Regardless, this is an advantage to students as they are now exposed to more than one variety of English and that English is not at all rigid to one. Moving on, most of the positive comments talk about NESTs' knowledge in slang words:

16) The ETA can explain the slang words easily. (SS14, NEST, +)

An example of statement that supported NNESTs:

17) Non-native teachers can give definitions to words we do not understand. Sometimes, they might give us the words in Malay.

There were no negative comments for NNESTs in this category. Thus, both NESTs and NNESTs are competent in teaching vocabulary. However, a critique about using the first language in a second language class by the NNESTs is it is bound to allow for "direct method" to take place.

3.5. Culture

There were several students who discussed the teaching of culture in the English class. 20 students wrote positively about NEST during the pre-test and another 5 students added to the number later during the post-test. Along with the positive reception from students, there were also 2 negative comments from them about NESTs at the end of the study. Contrastively, when initially there were 5 negative views for the NNESTs, but the number went nil at the end of the study. The number of positive comments for NNESTs also shows an improvement. An example of a positive comment is as follows:

18) When I speak to the ETA, I learn about the American culture. I now know that they like to be called by their first names instead of "cikgu (teacher)". (SS19, NEST, +)

This example shows how students may benefit from studying with NESTs and learn their culture while the following comment exhibited how the exchange of culture took place in the process: 
19) I never do this before but with the ETAs, I feel proud when they ask about my culture. This is the first time when people are truly interested to learn about my place. I explain to them in English. The best moment when the ETAs tried to eat durian... and now most of them will ask for roti canai and teh tarik. (SS23, NEST, +)

The cultural learning was twofold. The NESTs learned about the local culture from students and in the process, they introduced their American culture to the students. This also sets an excellent example of how we can combine cultural aspects with real-life communicative situations that help students relate with the language they are speaking. Additionally, 5 students found that NEST can be a source of cultural knowledge. This can be viewed in the following example statement:

20) Sometimes, there are words that we do not understand because they are really strange as we have never heard of them before. ETAs can explain to us and it becomes like a culture class. In turns out many of the words have interesting story behind them. Idioms are almost alien to us but when we the ETA told us the meaning and even drew pictures when explaining, we can understand the words better. (SS15, NEST, +)

However, students were sceptical of NNESTs during the pre-test. This could be ruled back because the culture belongs to the native speakers. Language can be learnt but culture is one's identity that cannot be emulated easily. One example of the negative comment was this:

21) It is not the same. No matter how badly my non-native teachers try to explain the culture or the origin of a word, I still feel it fake.

The quote shows that some students feel that no matter how learned a person is in a language, it will not be the same when learning from someone who lived in that culture. As it seems, one will always maintain their cultural heritage, which will eventually influence their teaching accuracy.

On a different vein, the NESTs also receive few negative comments:

22) I somehow disagree with some of the things said by the ETA. I dislike the idea of total freedom and do whatever we want and what we feel right.

Students can negatively receive the cultural exchange due to the clash of opinion. Despite that, further discussion will not be done here as it is not part of the current study.

\section{b. Teaching Styles}

For the teaching styles, there were two categories of comments assigned to them: 'ability to answer questions' and 'teaching methodology'. Below Table 2 is the distribution of the comments in these categories.

Table-2. Distribution of comments for 'teaching styles' group.

\begin{tabular}{l|l|c|c|c|c}
\hline \multicolumn{2}{c}{} & \multicolumn{3}{c}{ NESTs } & \multicolumn{2}{c}{ NNESTs } \\
\cline { 3 - 6 } & & + & - & + & - \\
\hline \multirow{2}{*}{ Ability to answer questions } & Pre & 3 & 0 & 0 & 0 \\
\cline { 2 - 6 } & Post & 3 & -15 & 20 & 0 \\
\hline \multirow{2}{*}{ Methodology } & Pre & 5 & 0 & 6 & 0 \\
\cline { 2 - 6 } & Post & 10 & -2 & 12 & 0 \\
\hline \multirow{2}{*}{ Total } & Pre & 8 & 0 & 6 & 0 \\
\cline { 2 - 6 } & Post & 13 & -17 & 32 & 0 \\
\hline
\end{tabular}

As presented by the table above, there were a total of 14 comments at the beginning and 62 comments in the end. There were 8 positive comments for NESTs and 6 positive comments for NNESTs initially. The numbers increase during the post-test but with sudden appearance negative comments for NESTs in both categories that totalled up to 17. Oppositely, NNESTs had been consistently not receiving any negative comment from either of the categories but a noticeable increase from 6 to 32 positive comments in the post-test. The two categories will be discussed in more details as follows:

\subsection{Ability to Answer Questions}

Teachers' availability and ability to give explanation and answers to students' questions. This category will also take into account students' satisfaction at receiving their teachers' feedback. There were 38 statements whereby all the 15 negative statements during the post-test were for NESTs while all comments for NNESTs were positive. These statements from students will exemplify the case:

23) Whenever I want to ask a question, it will always be the non-native teacher who will give me a conclusive answer. The ETAs rarely give me satisfactory answers and always say they do not know. A teacher should be able to answer most of our questions. (SS12, NEST, -)

This statement suggests that most of the times NESTs cannot provide 'satisfactory answers' to students' questions and this caused the students to be infuriated by the lack of professionalism from NESTs. In contrast, NNESTs responses satisfied them. Another student wrote:

24) The ETAs always ask us to ask our non-native teachers for confirmation. In the end, I will just ask my non-native teachers. (SS17, NEST, -)

25) "It is not a bad thing but, I guess the ETAs only want us to speak in class. Not much of writing is done. And sometimes I feel that there are things easier to be explained in BM.” (SS1 1, NEST, -)

The students also think that NESTs can be a bit impatient when answering questions. Partly because they do not apply enough teacher waiting time:

26) I have trouble when asking questions in English. The words will not come out fast. The ETAs can sometimes look blank and will try to finish my words fast. In the end, my question wasn't answered. (SS10, NEST, -)

Despite the fact the student's statement did not imply that NESTs are terrible at answering questions, they did agree on one thing - NNESTs were the better teachers. Additionally, this category also helps to reflect students' 
preferences in error corrections - to what degree do students agree on a communicative or prescriptive style of the teachers' teaching.

\subsection{Teaching Methodology}

On the same vein, students felt that NNESTs employed better teaching methodologies than NESTs despite the teachers using traditional teaching methods. Few students also wrote down about the ideal feats in teaching methodology found in NNESTs including: flexibility, innovative teaching method as well as being empathetic (second language learners) in the teaching that can make NNESTs:

27) ETAs know how to tackle any difficulties that I face as a learner because they used to be students just like me. They had gone through what I am now facing. (SS25, NNEST, +)

28) What I like about the Malaysian teacher is that they have many ways of teaching. I sometimes like the old way when the teacher will be in front. It is easier to understand rather than when I need to think what the teaching is trying to teach that day (implicit teaching). (SS2, NNEST, +)

29) They used to learn English. They got A. So, they are able to use their experience to help students like me. If one way doesn't work, they will come out with another way next time. (SS 1, NNEST, +)

30) What I like about non-native teachers is that they understand students well. They know how to help and how I feel. (SS11, NNEST, +)

Contrastively, 2 students view NESTs' teaching methodology inadequate, and they did not apply suitable teaching methods. When planning an input, it is crucial to set an appropriate context. The ideal input for acquiring a second language should also be comprehensible, relevant to their immediate interest, not too complex but not strictly graded either:

31) The ETA can sometimes give us tasks that are too simple or that can be too complicated. She never gives us homework. I like it at first but when I see my exam results, I want more homework. (SS4, NEST, -)

32) There was a lesson that I cannot understand what was going on. She was speaking in front about the history of the US...I think and then suddenly there was a laughter. I laughed along because I don't want to be different. It was weird. (SS6, NEST, -)

Most of the NESTs, and in this case, the ETAs do not receive any formal education on teaching methodologies. They only rely on crash courses that were merely designed to introduce them to what teaching in a classroom will look like. Of course, a short course in teaching is no match to a full degree in teaching. Students have different preferences, and, none of them, are created equal. Some of them would prefer to have more images in class, or prefer to have more role-plays as class activities. A good teacher will try to accommodate all these different learning strategies. This comes through years of experience and training.

Both types of teachers seem in favour of in applying for group work in class regularly. This was observed by the comment below:

33) When I attend the ETA class, I will mostly sit in groups. The Malaysian teachers start to do the same too...we start with pair work and then groupwork (SS6)

One reason why the NNESTs start to decentralise the class, and makes the class more student-centred due to the rise of the $21^{\text {st }}$ Century Learning movement when it aims to produce autonomous students who will take charge of their own learning.

Additionally, these NESTs were still young. Hence, that might explain why some play the safe card by bringing feasible activities rather than experimenting with other possibilities in teaching. NNESTs on the other hand, having years of experience will be more confident and have contingency plans at hand.

\section{c. Personal Factors}

Three categories were assigned together in a group known as 'personal factors'. Below Table 3 is the data distribution of these comments:

Table-3. Distribution of comments for the personal factors.

\begin{tabular}{l|l|c|c|c|c}
\hline \multicolumn{2}{c}{ Table-3. Distribution of comments for the personal factors. } \\
\cline { 3 - 6 } & & \multicolumn{2}{c|}{ NESTs } & \multicolumn{2}{c}{ NNESTs } \\
\cline { 3 - 6 } & & + & - & + & - \\
\hline \multirow{2}{*}{ Experience as an ESL learner } & Pre & 0 & -10 & 15 & 0 \\
\cline { 2 - 6 } & Post & 0 & -20 & 20 & 0 \\
\hline \multirow{2}{*}{ Hard-work } & Pre & 0 & 0 & 4 & 0 \\
\cline { 2 - 6 } & Post & 2 & 0 & 10 & 0 \\
\hline \multirow{2}{*}{ Affect } & Pre & 6 & 0 & 4 & 0 \\
\cline { 2 - 6 } & Post & 20 & 0 & 10 & 0 \\
\hline \multirow{2}{*}{ Total } & Pre & 6 & -10 & 23 & 0 \\
\cline { 2 - 6 } & Post & 22 & -20 & 40 & 0 \\
\hline
\end{tabular}

There was a total of 39 comments initially. Later, the number increased to 82. Like the previous category, NNESTs receive no negative comment at all while the number of negative comments increased by 10 for NEST. On the flip side, their number of positive comments increased too.

\subsection{Experience as an ESL Learner}

This was the largest category for personal factors with 65 comments. At the beginning there were 15 comments that stated that NNESTs were better teachers because they had the experience of learning English as second language, while the other 10 comments perceived NESTs as inadequate because they did not know how it felt to learn English themselves. It was also alarming to see the negative comments for NESTs doubled up in the post-test.

NESTs were viewed poorly when it came to teaching grammar, especially because of the almost to nonexistent experience as second language learners in English. The following statement exemplifies this: 
34) The ETAs never learn English as to how we do. They do not learn English as another language or become a student to learn it. It is like BM (Bahasa Malaysia) to us and English to them. They never learn grammar in class. It is already a language that they have been speaking every day. That's why they do not know how to teach grammar. (SS9, NEST, -)

The majority of the students in these students believe that NESTs are insensitive to possible students' problems in learning the language, and therefore, the strength of NNESTs is that they are more emphatic as they used to be second language learners, specifically in English. The experience as second language learners is invaluable as from that, the teachers will be able to come out with strategies that they found useful for their students.

35) My Malaysian teachers used to be students too. Sometimes, they would share the techniques they had worked and used during their time as students. Those techniques are easy to follow and often help my friends who are weak in the subject (SS10, NNEST, +).

36) I like to listen to my non-native teacher's story of how she learns the language. Just like me, no one in her family can speak English but amazingly, she can become an English teacher. She's really inspiring. (SS18, NNEST, +)

From the above statement, NNESTs often discussed their experience as second language learners with their students and became the second language interpreters. Students will have an instant connection and able to use establish trust rapport with their students. These NNESTs provide empathy that NESTs most of the time failed to do such since they used to experience learning the target language as a second language. Additionally, they also use this opportunity to motivate their students and send the message across - that nothing is impossible. If their teachers can do it, so does the students.

\subsection{Hard-Work}

There were 16 comments in this category. All of the comments were positive. This suggests that all the teachers, regardless of their background are hardworking to the students. Some students deem hardworking as the effort of the teachers in school, while others value hardworking as to how much effort has been put in order for the teachers to be an English teacher. For the first, students see NESTs as hardworking when:

37) The ETAs sometimes bring games and speakers to class. That's hardworking to me. (SS20, NEST, +) As to the latter, a comment that exemplifies this situation:

38) One of the non-native teachers used to study in the UK just to learn how to teach English. If that is not an effort, I don't know what is (SS23, NNEST, +).

Another student stated this:

39) My teacher always comes out with interesting worksheet for us to do. I know they are not easy to do. She will get them photocopied and never ask from us money. I really appreciate them because I know she thinks a lot about us when designing one. (SS12, NNEST, +)

Many of the comments were mainly about NNESTs. However, this does not connote the idea that native speakers are not equally hardworking, but this is perhaps due to the definition of hard-work to the students themselves - hard-work is when you need to put a lot of effort into becoming an English speaker. This is true when NNESTs feel that they have to work harder to prove themselves worthy. Proven, students do acknowledge this effort appreciate NNESTs for this.

\subsection{Affect}

There were 40 statements made in this category, and there were no negative comments issued too. Though both were received positively, it appeared that NESTs left more affective value to students. The following statement comes from a student who viewed positively on NESTs affective ability: 20 students perceived NESTs to leave them with more affective value while NNESTs only received 10 positive comments.

Although I can't speak fluently. Most of the times, I will speak in broken English, but the ETAs get me want to speak to them because they know my current favourite movies and artists. We then become close and I feel like they are my friends. (SS1, NEST, +).

NESTs are doing well at connecting with their students. Students tend to treat NESTs as friends rather as the more intimidating, teachers. This approach will work well to get students motivated to speak in the language as NESTs provide a genuine reason to do so - to talk about something they are interested in the real life. American entertainment is often the source of such interests. To illustrate, styles of music, fast food, video games and the social media. Apart from learning their culture, students seem elated to share common likings with NESTs.

40 ) In the evening, these ETAs sometimes join us to play football and sepak takraw. I am a bit shy when we're in class but I am confident to speak to the ETA when we're in a game (SS5, NNEST, +).

Students respond in agreement that most of NESTs were interested in learner's opinion. There are also seen to be more patient. NESTs were seen as more casual, caring, and patient. There was not much link whether these would result in positive overall on learning in the literature review.

The possible reason why NNESTs received fewer positive comments could be contributed by the fact how Malaysian value their teachers as superior and that there is a clear boundary of power that they should not trespass as students - power distance. Despite that, some teachers are friendly and choose to adapt to the friendlier version of teachers.

The results presented in the previous three sections can be presented in the following table Table 4: 
Table-4. Distribution of comments for NESTs and NNESTs across the three categories.

\begin{tabular}{|c|c|c|c|c|c|c|}
\hline & & & & NESTs & & NNESTs \\
\hline & & & Positive $(+)$ & Negative (-) & Positive (+) & Negative (-) \\
\hline \multirow{10}{*}{$\begin{array}{l}\text { Linguistic } \\
\text { factors }\end{array}$} & \multirow[t]{2}{*}{ Oral Skills } & Pre & 21 & $\mathrm{O}$ & 10 & -20 \\
\hline & & Post & 24 & -5 & 15 & -5 \\
\hline & \multirow[t]{2}{*}{ Literacy Skills } & Pre & 6 & $\mathrm{O}$ & $\mathrm{O}$ & $\mathrm{O}$ \\
\hline & & Post & 8 & -2 & 20 & O \\
\hline & \multirow[t]{2}{*}{ Grammar } & Pre & 25 & $\mathrm{O}$ & 10 & -8 \\
\hline & & Post & 10 & -15 & 25 & $\mathrm{O}$ \\
\hline & \multirow[t]{2}{*}{ Vocabulary } & Pre & 26 & $\mathrm{O}$ & 18 & $\mathrm{O}$ \\
\hline & & Post & 28 & -2 & 20 & O \\
\hline & \multirow[t]{2}{*}{ Culture } & Pre & 20 & $\mathrm{O}$ & 15 & -5 \\
\hline & & Post & 25 & -2 & 12 & $\mathrm{O}$ \\
\hline \multirow{4}{*}{$\begin{array}{l}\text { Teaching } \\
\text { styles }\end{array}$} & \multirow[t]{2}{*}{ Ability to answer questions } & Pre & 3 & $\mathrm{O}$ & $\mathrm{O}$ & 0 \\
\hline & & Post & 3 & -15 & 20 & $\mathrm{O}$ \\
\hline & \multirow[t]{2}{*}{ Methodology } & Pre & 5 & $\mathrm{O}$ & 6 & $\mathrm{O}$ \\
\hline & & Post & 10 & -2 & 12 & 0 \\
\hline \multirow{8}{*}{$\begin{array}{l}\text { Personal } \\
\text { factors }\end{array}$} & \multirow[t]{2}{*}{ Experience as an ESL learner } & Pre & $\mathrm{O}$ & -10 & 15 & $\mathrm{O}$ \\
\hline & & Post & 0 & -20 & 20 & $\mathrm{O}$ \\
\hline & \multirow[t]{2}{*}{ Hard-work } & Pre & $\mathrm{O}$ & $\mathrm{O}$ & 4 & $\mathrm{O}$ \\
\hline & & Post & 2 & 0 & 10 & $\mathrm{O}$ \\
\hline & \multirow[t]{2}{*}{ Affect } & Pre & 6 & $\mathrm{O}$ & 4 & $\mathrm{O}$ \\
\hline & & Post & 2 & $\mathrm{O}$ & 10 & $\mathrm{O}$ \\
\hline & \multirow[t]{2}{*}{ Total } & Pre & 112 & -10 & 82 & 33 \\
\hline & & Post & 112 & -63 & 164 & 5 \\
\hline
\end{tabular}

The above table helps to identify the strengths and weaknesses of NESTs and NNESTs as indicated by students in the study. What is interesting is that the frequency distribution of the two groups of teachers is complementary. To illustrate, when NNESTs are better at teaching grammar and literacy skills, NESTs better at teaching oral skills. The graph also displays that NNEST's strongest trait in this is their ability to teach grammar and literacy skills.

The most robust finding here for NESTs is that they are perceived to be the best in teaching oral skills and vocabulary. Also, NESTs are also perceived as better in teaching culture. Despite that, few students perceived them as being inadequate when teaching grammar. Additionally, quite many students deemed NESTs were not always able to answer questions especially grammar questions.

It is also interesting to see the number of positive comments for NNESTs doubled in the post-tests and that the number of negative comments was reduced. It can be assumed that students' personal bias towards a certain teacher, individual personality clashes between the student and teacher during the pre-test. Pre-judgmental thoughts that NESTs are better models of language could be why students were not keen to have NNESTs as their teachers. Contrastively, the number of positive comments received by NESTs remained the same throughout the study, while the number of negative comments increased. The latter could be because the vast majority of the students felt that it did not matter if the teacher was native or non-native as long as they were good teachers.

Students mentioned characteristics that favoured NNESTs including the teaching of literacy skills and grammar, their ability to use appropriate teaching methodologies, their satisfactory ability to answer students' questions, and their experience as second language learners could provide students with emotional support. However, NNESTs were also criticised for not able to teach the oral skills well. This was due to the preconceived judgment that only native speakers are the perfect models for the language.

Students' preference of NNEST teaching methodology and ability to give feedback is especially impressive when considered in light of the research conducted in the 1980s. In the 80's there was a perception that to become good teachers, NNESTs should improve their linguistic skills to match those of native speakers, but they should adopt the teaching practices and methods of NESTs. However, the results from the present survey of student perceptions disregard the need for NNESTs to become native-like in their pedagogical practices. NNESTs have unique characteristics that students find lacking in NESTs, especially in the teaching of grammar and the ability to answer questions. Acquiring a native-like sensitivity is not 'a proper goal' for NNESTs. Rather, the unique teaching abilities of both NESTs and NNESTs complement each other and provide a better learning environment to ESL students.

Students also perceived NNESTs to be more understanding and empathetic towards them. They felt that NNESTs could provide affective support that NESTs were not equipped to due to their experience as ESL learners. As a result of NNESTs experience of being ESL learners, their teaching methodology may fit their students' expectations. The skills that a person has do not necessarily translate into teaching ability. Thus, the student felt that NNESTs could teach them how to 'enjoy' English, and be able to provide appropriate answers to their questions. While this student believes that NNESTs can be good teachers, their argument suggests that they do not consider NNESTs to be as skilled as NESTs. This perception of NESTs as being more skilled in their language competence was shared by a majority of the students in their essays.

Most of the current study students agreed that NNESTs are good at teaching most of the skills except speaking and vocabulary. This perception of NNESTs' less-than-native-like pronunciation is one possible reason why none of the students stated that NNESTs provided them an imitable model. None of the students' essays in this study discuss the role of NNESTs as providing good learner models. Students only refer to NNESTs experience as ESL learners concerning their ability to better answer students' questions, provide empathy, and use appropriate teaching methodologies. They do not feel, or at least explicitly state, that these NNESTs provide them with good learner models. 


\subsection{Students' Perception and Attitudes}

The idea of having exposure to NESTs will result in a positive acquisition of the desired second language comes from Little \& Saville-Troike's "language sample" theories. As the starting point, their theories imply that learners need to be exposed to adequate language models for them to acquire the target language proficiently. A question is raised when deciding which model is ideal for second language learning - the NEST or the NNEST. Researchers like Medgyes, Braine and Littlewood (Braine, 1999; Littlewood, 1984; Medgyes, 1994) contended that both groups have their advantages and disadvantages.

The study Sahin (2005) discovered that students who are introduced to the teaching of English from NESTs will tend to have positive attitudes towards the target language and they would tend to be more cooperative in English lessons. This is compared to those who are only exposed to NNESTs. Despite that, there is no available evidence that shows that by being exposed to NESTs, students will perform better in their studies. Regardless, as evident in Sahin's and this study, students have more positive attitudes towards the language.

The outcome of this study was that students viewed NESTs as the model of the target language, and better at teaching oral skills. They also viewed NESTs the best at teaching vocabulary and culture. Despite that, few students feel that NESTs are not able to teach grammar well, and they are not always able to answer their questions. This could be due to their lack of experience in learning a second language or teaching methodology. Students also view NNESTs as the interpreter of the target language and are good at teaching grammar compared to NESTs.

\subsection{Collaborative Teaching}

Among many of the comments in this study, there was one common idea mentioned by quite a number of them, "collaborative teaching" of the target language. They believe that collaborative teaching between the two types of teachers would make their language learning to be more productive:

"I like to see my teachers teaching together. The ETA can teach us pronunciation while madam L will

teach us how to score in the examination. We can also have more activities because there are 2 teachers teaching at the same time." (SS17).

Students seem to realise that of the shortcomings from each teacher, they can complement each other. When the weakness is in teaching grammar, NNESTs can help to accommodate that. Similarly, NESTs can become the language model while NNESTs have the advantage of becoming second language learners that they can share their learning strategies with their students. This finding is an eye-opener because each of the teacher has their own strengths and weaknesses. Instead of chastising them for their inadequacy, these students believe in a collaborative effort as it will provide a better teacher-learning setting for them.

There were a few limitations to the study. First, there were only 30 respondents from a rural school. Their perceptions may not represent the majority of students in Malaysia. Therefore, future research may take into consideration of applying the same study in an urban school. Second, the NESTs only teach these students for at least one year. We cannot see what changes they would have made if they had continued teaching. Therefore, a longitudinal study is needed to see the effect it has on students' perceptions.

Despite the limitations of this study, its results may help teachers and language programme administrators to respond to students' doubts and prejudices against NNESTs. These results may also inspire teacher preparation programme to stop striving traditional native speaker and useful teacher notions. Since this study was only done through essay writing, it could only provide some insightful ideas on the issues of NESTs and NNESTs. Further studies that employ mixed methods (of questionnaires and interviews) are recommended to understand more about these two teachers. It is also hoped that there will be studies on students' expectations of what constitutes a good teacher.

\section{Conclusions}

In a nutshell, this study aimed to investigate students' perceptions towards NESTs and NNESTs, respectively. One of the most essential variables in second language teaching is the teachers themselves. The differences between the two types of teachers were noticed and acknowledged by students. Their skills and personality will determine the best conditions fit for learning to take place. This study was conducted to see whether the students' perception towards NESTs and NNESTs change over time by administering pre- and post-test essay writing to students who were taught by both teachers in a year.

English as a lingua franca is the product of globalization, and as borders between different cultures are disappearing, so are the borders that once held English to a "standard" controlled by "inner-circle" countries (Kachru, 2006). This perspective then contested theories such as Kachru's "inner-circle" prestige ideology as it assumes a more pluralistic stance whereby the inner-circle members will now be measured by proficiency, not birth place. English is now the language of communication and it has been widely used across the world. This makes it more difficult to tell between a second language speaker and a foreign language speaker. On the same note, a study by Benke and Medgyes (2005) challenged the prestige given to NESTs, instead chose to give recognition to the advantages of both types of teachers. Their study managed to prove that both groups are on par with each other. Despite the differences between the two teachers, that will not make one better that the other.

The English proficiency of English teachers must be viewed pluralistically - it should no longer be defined by the ambiguous notion of native versus non-native speakers but, instead, should be determined by whether one is a novice or an expert as English today is no longer dominated by the traditional inner circle (Kachru, 1988). The "native speaker" notion as introduced by Chomsky (1986) had become obsolete as there are growing numbers of people who can speak more than one language or more than one variety of a language. Consequently, a "good teacher" will no longer be identified by the obsolete and ill-defined native/non-native model but rather as a person who has mastered a combination of linguistic and pedagogical skills.

In an attempt to validate the previous study done in the area of NEST and NNEST comparison. The present research revealed some interesting, yet contradictory results. The results of the current study are parallel to Benke and Medgye's study and confirm that students do in fact see differences between their NESTs and NNESTs. The 
vast majority felt that it did not matter if the teacher was native or non-native "as long as they were good teachers". An analysis to the results of this study had confirmed that students might seem unclear of what defines as NESTs and NNESTs initially. Their perceptions and attitudes change towards the end even favour NNESTs later - their perception does significantly become more positive or negative over time.

\section{References}

Abdullah, Y. L. P. K., Yunus, M. M., \& Hashim, H. (2019). Grammatical errors in ESL writing: An error analysis. International Journal of Recent Technology and Engineering, 8(2), 302-307.

Abdullah., A. N. M., Yunus, M., Hashim, H., Sayadi, S. S., Seman, N. A., Ibrahim, Z. B., \& Zakaria, N. A. A. B. (2019). Interference of first language in secondary school students. International Journal of Engineering and Advanced Technology, 8(6S3), 675-681.

Árva, V., \& Medgyes, P. (2000). Native and non-native teachers in the classroom. System, 28(3), 355-372.

Babchuk, W. (1997). The rediscovery of grounded theory: Strategies for qualitative research in adult education. Lincoln: The University of Nebraska.

Benke, E., \& Medgyes, P. (2005). Differences in teaching behaviour between native and non-native speaker teachers: As seen by the learners. In E. Llurda, Non-native language teachers: Perceptions, challenges, and contributions to the profession (pp. 195-216). New York: Springer.

Braine, G. (1999). NNS and invisible Bbarriers in ELT. TESOL Matters, 2(2), 14

Chomsky, N. (1986). Knowledge of language: Its nature, origin, and use. New York: Praeger.

Glaser, B., \& Strauss, A. (1967). The discovery of grounded theory: Strategies for qualitative research. Chicago: Aldine Publishing Company.

Hashim, H. U., Yunus, M. M., \& Hashim, H. (2018). Language learning strategies used by adult learners of teaching English as a second language (TESL). TESOL International Journal, 13(4), 39-48.

Hashim., H., Yunus, M., \& Hashim, H. (2019). 3-minutes pitching with flip grid: An antidote of innovation for speaking anxiety. International Journal of Innovative Technology and Exploring Engineering, 8(7), 1798-1801.

Kachru, B. B. (1988). The sacred cows of English. English Today, 4(4), 3-8.

Kachru, B. B. (2006). World Englishes and culture wars. The Handbook of World Englishes, 446-471.

Krejcie, R. V., \& Morgan, D. W. (1970). Determining sample size for research activities. Educational and Psychological Measurement, 30(3), 607-610.

Littlewood, W. (1984). Foreign and second language learning: Language acquisition research and its implications for the classroom. Cambridge: Cambridge University Press.

Medgyes, P. (1994). The non-native teacher. London: Macmillan.

Moussu, L., \& Llurda, E. (2008). Non-native English-speaking English language teachers: History and research. Language Teaching, 41(3), 315-348.

Reves, T., \& Medgyes, P. (1994). The non-native English speaking EFL/ESL teacher's self-image: An international survey. System, 22(3), 353-367.Available at: https://doi.org/10.1016/0346-251 x(94)9002 1-3.

Sahin, İ. (2005). The effect of native speaker teachers of English on the attitudes and achievement of learners. Journal of Language and Linguistic Studies, 1(1), 1-14. 